\title{
What Is Required for Highly Oxidized Molecules To Form Clusters with Sulfuric Acid?
}

\section{Elm, Jonas}

2017-05-31

Elm , J , Myllys , N L P \& Kurten , T C 2017 , ' What Is Required for Highly Oxidized Molecules To Form Clusters with Sulfuric Acid? ' , Journal of Physical Chemistry A, vol. 121 pÿ, no. 23 , pp. 45784587 . https://doi.org/10.1021/acs.jpca.7b03759

http://hdl.handle.net/10138/271659

https://doi.org/10.1021/acs.jpca.7b03759

acceptedVersion

Downloaded from Helda, University of Helsinki institutional repository.

This is an electronic reprint of the original article.

This reprint may differ from the original in pagination and typographic detail.

Please cite the original version. 


\title{
What is Required for Highly Oxidized Molecules to Form Clusters with Sulfuric Acid?
}

\author{
Jonas Elm, ${ }^{*} \dagger$ Nanna Myllys, ${ }^{\dagger}$ and Theo Kurtén $\ddagger$ \\ Department of Physics, University of Helsinki, Finland, and Department of Chemistry, \\ University of Helsinki, Finland \\ E-mail: jonas.elm@helsinki.fi
}

${ }^{*}$ To whom correspondence should be addressed

${ }^{\dagger}$ University of Helsinki

${ }^{\ddagger}$ University of Helsinki 


\begin{abstract}
We have studied the specific requirements of a given neutral organic molecule to act as a stabilizer in sulfuric acid induced new particle formation. Based on an analysis of the reaction Gibbs free energies between simple functional groups and sulfuric acid, carboxylic acid groups are identified to show the strongest hydrogen bonding interaction with sulfuric acid. The free energy associated with the hydrogen bonding between sulfuric acid and 14 different carboxylic acids of atmospheric relevance reveal that the binding strength is very dependent on the ability of sulfuric acid to form an additional hydrogen bond via its vacant $\mathrm{S}-\mathrm{OH}$ group to a $\gamma$-carbonyl group in the organic molecule. Extending the analysis to monoterpene oxidation products and further to large dimer esters, we identify the following necessary criteria for a given organic oxidation product to efficiently stabilize sulfuric acid clustering: 1) weak or no intramolecular hydrogen bonds in the isolated monomer; 2) more than two carboxylic acid groups. As a proof of concept we show that these requirements corresponds to the docking of a sulfuric acid molecule in between two non-interacting carboxylic acid groups in the organic molecule. These findings suggests that for a given organic oxidation product to participate in the initial steps in new particle formation involving sulfuric acid, very distinct molecular features are required.
\end{abstract}




\section{Introduction}

Clustering of organic and inorganic acids is an important process in the atmosphere, leading to the formation of new particles. ${ }^{1}$ Newly formed particles can grow to larger sizes, eventually acting as cloud condensation nuclei $(\mathrm{CCN})$. Atmospheric aerosol particles and especially their interaction with clouds remain the largest uncertainty in current climate modelling and estimation. Using global models it has been estimated that up to half the number of $\mathrm{CCN}$ in the atmosphere originates from nucleation. ${ }^{2}$

In marine environments iodine species are believed to form new particles. ${ }^{3}$ Especially, iodic acid is believed to be a key component via clustering with itself and water. ${ }^{4}$ Over land sulfuric acid is believed to be one of the main drivers for the formation of new particles in the atmosphere, ${ }^{5}$ by clustering with for instance various bases. ${ }^{6}$ Experimental evidence suggests that organic acids can enhance sulfuric acid new particle formation. ${ }^{7}$ Highly oxidized multifunctional compounds (HOMs), has also been inferred to be important species in the initial steps in new particle formation involving sulfuric acid, ${ }^{8-10}$ but the exact interaction at the molecular level and identity of the reacting species still remain unknown. The molecular structure of HOMs originating from cyclohexene ozonolysis has been resolved using a combination of experimental and theoretical methods. ${ }^{11,12}$ Autoxidation is believed to be an important source of HOMs, ${ }^{13-17}$ however this process often leads to the formation of peripheral peroxyacid functional groups forming strong intramolecular hydrogen bonds, and the formed compounds might have high vapour pressures despite having a high oxygento-carbon content. ${ }^{18}$ For instance recent computational studies have shown that a $\mathrm{C}_{6} \mathrm{H}_{8} \mathrm{O}_{7}$ autoxidation product from cyclohexene ozonolysis binds very weakly to sulfuric acid. ${ }^{19,20}$

The identification of the participating species is complicated by the fact that directly measuring the initial steps in sulfuric acid cluster formation is very difficult. A promising technique is the combination of Fourier transform infrared (FT-IR) spectroscopy experiments and quantum chemical calculations. Using these techniques a wide range of direct hydrogen bonded interactions has been elucidated, such as $\mathrm{O}-\mathrm{H} \cdots \mathrm{X}$ and $\mathrm{N}-\mathrm{H} \cdots \mathrm{X}$, where $\mathrm{X}$ is either 
$\mathrm{O},{ }^{21-25} \mathrm{~N},{ }^{26-31} \mathrm{~S}^{21-24}$ or $\mathrm{P},{ }^{32,33}$ by assigning the specific hydrogen bonded interaction to a red-shift in the vibrational frequency compared to the isolated monomers. However, the FT-IR method has currently only been utilized on weakly bound complexes, as stronger interactions, such as in sulfuric acid clustering, will eventually lead to the formation of various larger clusters, which makes it difficult to assign the observed red-shift to a specific cluster.

To identify sulfuric acid clustering, Chemical Ionization (CI) with Atmospheric Pressure interface Time-Of-Flight mass spectrometers (APi-TOF) ${ }^{34}$ or chemical ionization mass spectrometers (CIMS) such as the Cluster CIMS ${ }^{35}$ can be utilized. The ionization reagent has usually been nitrate ions, ${ }^{10,36,37}$ but recent advances has shown varying selectivity of other reagent ions such as acetate ${ }^{38-40}$ and iodine. ${ }^{41,42}$ The charging process will inevitably lead to a change in the cluster composition, which implies that the detected cluster might not be the one which was formed initially. The exact involvement and enhancing effect of HOMs in sulfuric acid new particle formation, thereby remains an unresolved issue.

Using computational methods, we herein explore the requirements of a HOM to form strong hydrogen bonded molecular clusters with sulfuric acid. Starting from simple functional groups, we stepwise narrow down the exact requirement for forming strong hydrogen bonded clusters with sulfuric acid. For each step we increase the size of the molecular system, moving towards the interaction between sulfuric acid and large molecular weight dimer esters.

\section{Methods}

\subsection{Computational Details}

All density functional theory geometry optimizations and vibrational frequency calculations were carried out in Gaussian09 rev B.01. ${ }^{43}$ A tight convergence criteria was employed for the calculations performed in section 3.1, as imaginary frequencies emerged in the methyl 
group rotation. All other calculations employed default convergence criteria. Explicitly correlated coupled cluster calculations $\left(\mathrm{CCSD}(\mathrm{T})-\mathrm{F} 12 \mathrm{a}^{44-46}\right.$ with VXZ-F12, $\left.{ }^{47} \mathrm{X}=\mathrm{D}, \mathrm{T}\right)$ were calculated using the Molpro 2012 program. ${ }^{48}$ Domain based local pair natural orbital coupled cluster calculations - DLPNO-CCSD(T) - were run with ORCA 3.0.3. ${ }^{49}$ Thermochemical parameters are calculated using rigid rotor and harmonic oscillator approximations and all values are reported at $298.15 \mathrm{~K}$ and $1 \mathrm{~atm}$.

We utilize the DFT functionals M06-2X, PW91 and $\omega$ B97X-D, as they have shown good performance in benchmark studies for obtaining the structures, ${ }^{50}$ electronic energies ${ }^{51-53}$ and Gibbs free energies ${ }^{50,54,55}$ of atmospheric molecular clusters involving sulfuric acid. For all DFT calculations the $6-31++\mathrm{G}(\mathrm{d}, \mathrm{p})$ basis set was used. The mean absolute error in the thermal contribution for using the $6-31++\mathrm{G}(\mathrm{d}, \mathrm{p})$ basis set compared to a large aug-ccpV5Z basis set has recently been shown to be below $0.5 \mathrm{kcal} / \mathrm{mol}$ for a test set of 6 small cluster reactions involving sulfuric acid. ${ }^{56}$ Furthermore, it has been demonstrated that the reduction from the larger $6-311++\mathrm{G}(3 \mathrm{df}, 3 \mathrm{pd})$ basis set to $6-31++\mathrm{G}(\mathrm{d}, \mathrm{p})$ have little effect on the thermal contribution to the Gibbs free energy using a large test set of 107 atmospherically relevant clusters. ${ }^{57}$

To identify the lowest free energy structure of the organic compounds, each monomer was initially scanned using a systematic rotor approach with a MMFF94 force field as implemented in Avogadro. ${ }^{58}$ Subsequently, the amount of conformers were narrowed down using M06-2X/6-31++G(d,p) yielding 1-6 conformations depending on the compound. To identify the sulfuric acid - organic compound cluster structures all the identified organic monomer conformations were subjected to a sampling of the configurational space using a semi-empirically guided technique. For each conformation 300 randomly oriented $\mathrm{H}_{2} \mathrm{SO}_{4}$ molecules are distributed around the target organic compound and optimized with the semiempirical PM6 method. All the converged structures were ranked by the electronic energy and dipole moment based on a M06-2X/6-31++G(d,p) single point energy calculation. All identified conformations were subsequently optimized and vibrational frequencies are calcu- 
lated at the M06-2X/6-31++G(d,p) level of theory. All the conformations within $6 \mathrm{kcal} / \mathrm{mol}$ are subsequently also calculated using PW91/6-31++G(d,p) and $\omega$ B97X-D/6-31++G(d,p). We use DFT for obtaining the geometry and frequencies (i.e. the $\Delta G_{\text {Thermal }}$ contribution) and then use a higher level of theory for obtaining the binding energy $\left(\Delta E_{\text {bind }}\right)$, calculated on top of the DFT geometry. The approximate $\Delta G_{\text {bind }}^{\mathrm{CCSD}(\mathrm{T})-\mathrm{F} 12 \mathrm{a}^{*}}$-value is calculated as follows:

$$
\Delta G_{\text {bind }}^{\mathrm{CCSD}(\mathrm{T})-\mathrm{F} 12 \mathrm{a}^{*}}=\Delta E_{\text {bind }}^{\mathrm{CCSD}(\mathrm{T})-\mathrm{F} 12 \mathrm{a}}+\Delta G_{\text {Thermal }}^{\mathrm{DFT}}
$$

This calculation is performed for each of the functionals (M06-2X, PW91 and $\omega$ B97X-D) and the final Gibbs free energy is presented as the average of the three results. To estimate the sensitivity of the calculated free energy on the functional used to obtain the geometry and vibrational frequencies, we report the scatter in the free energy as one standard deviation $(\sigma)$.

\section{Results and Discussion}

\subsection{Interaction between $\mathrm{H}_{2} \mathrm{SO}_{4}$ and Common Functional Groups}

To get an indication of the binding strength between sulfuric acid and HOMs, we initially study a range of common organic functional groups: alcohol (methanol), carbonyl (propanone), ether (dimethylether), ester (methylformate), peroxide (methylhydroperoxide), carboxylic acid (acetic acid) and peroxy acid (formic peroxy acid). Table 1 presents the calculated average reaction free energies for the cluster formation between sulfuric acid and the different functional groups. The geometries and frequencies were obtained using DFT/6$31++\mathrm{G}(\mathrm{d}, \mathrm{p})$ with a tight convergence criteria and all three functionals identified the same cluster as the lowest free energy minimum. The single point energies were calculated at the $\operatorname{CCSD}(\mathrm{T})-\mathrm{F} 12 \mathrm{a} / \mathrm{VTZ}-\mathrm{F} 12$ level of theory. 
Table 1: Average free energy for the cluster formation between sulfuric acid and common functional groups. +/- refers to whether the functional group is participating as an acceptor/donor or both. Calculations were performed at $298.15 \mathrm{~K}$ and $1 \mathrm{~atm} . \Delta E$ and $\Delta G$ are reported in $\mathrm{kcal} / \mathrm{mol}$ and $\Delta S$ in $\mathrm{Cal} / \mathrm{mol} \cdot \mathrm{K}$.

\begin{tabular}{lccccc}
\hline \hline Functional Group & $\Delta G_{\text {F12/VTZ-F12 }}$ & $\Delta E_{\text {F12/VTZ-F12 }}$ & $\Delta S$ & Acceptor & Donor \\
\hline \hline Alcohol & $-2.9(0.2)$ & $-13.9(0.1)$ & $-32.1(1.1)$ & + & + \\
Peroxide & $-1.8(0.3)$ & $-14.6(0.0)$ & $-38.2(1.2)$ & + & + \\
Carbonyl & $-1.7(0.3)$ & $-13.9(0.2)$ & $-36.9(1.1)$ & + & - \\
Ester & $-1.9(0.2)$ & $-14.0(0.2)$ & $-36.5(0.3)$ & + & - \\
Ether & $-3.0(0.4)$ & $-14.5(0.2)$ & $-33.6(1.2)$ & + & - \\
Peroxy acid & $-1.4(0.2)$ & $-13.5(0.1)$ & $-36.7(0.3)$ & + & + \\
Carboxylic acid & $-6.7(0.1)$ & $-18.4(0.1)$ & $-36.4(0.3)$ & + & +
\end{tabular}

There is a negligible difference $(0.15 \mathrm{kcal} / \mathrm{mol}$ or less $)$ depending on whether a VDZ-F12 or VTZ-F12 basis set was employed in the calculation of the binding energy (see Supporting Information Table S1). The values obtained using the VTZ-F12 basis set are in all cases slightly more negative than the corresponding VDZ-F12 values. This shows that the VDZF12 basis set can be utilized without introducing any significant errors in the binding energies. Excluding the carboxylic acid ( $\Delta E$ up to $-18.4 \mathrm{kcal} / \mathrm{mol}$ ), the CCSD(T)-F12a/VTZ-F12 binding energies only varies between $-13.5 \mathrm{kcal} / \mathrm{mol}$ and $-14.6 \mathrm{kcal} / \mathrm{mol}$, in the case of the peroxy acid and peroxide, respectively. The thermal contribution to the Gibbs free energy of the studied functional groups is found to vary from $11.0 \mathrm{kcal} / \mathrm{mol}$ to $12.8 \mathrm{kcal} / \mathrm{mol}$ for the alcohol and peroxide, respectively. This illustrates that the binding free energy for these weakly bound clusters is very depend on both the binding energy, but also the entropy contribution contained in the thermal contribution.

The alcohol and peroxide predominantly bind to sulfuric acid by acting as a hydrogen bond donor $(-\mathrm{OH} \cdots \mathrm{O}=\mathrm{S}$ - and $\mathrm{OOH} \cdots \mathrm{O}=\mathrm{S})$, but secondary interactions are also seen from $\mathrm{S}-\mathrm{OH}$ to an oxygen atom in -OH and $-\mathrm{OOH}$ bonds. The interaction between sulfuric acid and the alcohol is $1.1 \mathrm{kcal} / \mathrm{mol}$ stronger than the peroxide $(-2.9 \mathrm{kcal} / \mathrm{mol}$ and -1.8 
$\mathrm{kcal} / \mathrm{mol}$, respectively). The carbonyl, ester and ether functional groups, exclusively act as hydrogen bond acceptors. The carbonyl group and the ester show similar binding, with a reaction free energy of $-1.7 \mathrm{kcal} / \mathrm{mol}$ and $-1.8 \mathrm{kcal} / \mathrm{mol}$, respectively. The ether interacts slightly stronger with sulfuric acid, with a reaction free energy of $-3.0 \mathrm{kcal} / \mathrm{mol}$. The peroxy acid has both a donor and an acceptor group, but the interaction with sulfuric acid is very weak, with a reaction free energy of $-1.4 \mathrm{kcal} / \mathrm{mol}$. We have previously identified that the weak binding between sulfuric acid and peroxy acids are caused by the internal hydrogen bond in the peroxy acid monomer (i.e. from the $-\mathrm{OOH}$ group to the $\mathrm{O}=\mathrm{C}$ ). This internal hydrogen bond needs to be broken to form a new hydrogen bond with sulfuric acid ${ }^{19}$ and causes the interaction of the peroxy acid to be significantly weaker (by $2.1 \mathrm{kcal} / \mathrm{mol}$ ) than the individual contributions from an peroxide $(-1.8 \mathrm{kcal} / \mathrm{mol})$ and a carbonyl group $(-1.7$ $\mathrm{kcal} / \mathrm{mol}$ ). The carboxylic acid interacts strongest with sulfuric acid, with a reaction free energy of $-6.7 \mathrm{kcal} / \mathrm{mol}$. This is a consequence of an almost co-planar hydrogen bond donoracceptor pair between the sulfuric acid and carboxylic acid. Furthermore, the sulfuric acid carboxylic acid interaction is found to be $-2.1 \mathrm{kcal} / \mathrm{mol}$ more favourable than the individual contributions from an alcohol $(-2.9 \mathrm{kcal} / \mathrm{mol})$ and a carbonyl group $(-1.7 \mathrm{kcal} / \mathrm{mol})$. This effect is caused by the fact that the binding energy and thermal contributions contribute to the free energy in opposite directions. The binding energy of the carboxylic acid is 9.4 $\mathrm{kcal} / \mathrm{mol}$ lower than the sum of the contributions from the alcohol and a carbonyl group (both $-13.9 \mathrm{kcal} / \mathrm{mol}$ ). However, the non-additivity is caused by the carboxylic acid having a similar thermal contribution $(11.7 \mathrm{kcal} / \mathrm{mol})$ as each of the individual functional groups (11.0 kcal for the alcohol and $12.2 \mathrm{kcal} / \mathrm{mol}$ for the carbonyl group). Hence the carboxylic acid group only suffers the entropy penalty once, where the sum of the two groups suffers it twice. As seen from Table 1, , clustering of a HOM with sulfuric acid will inevitably yield an entropic penalty of about $12 \mathrm{kcal} / \mathrm{mol}$ to the Gibbs free energy via the thermal contribution. Based on mass balance relations a given HOM (at ppt-ppb level mixing ratios) would require a reaction free energy of around $-12 \mathrm{kcal} / \mathrm{mol}$ to form stable clusters with sulfuric acid. ${ }^{59}$ 
Hence at least a reaction electronic binding energy of $-24 \mathrm{kcal} / \mathrm{mol}$ is required.

The sulfuric acid molecule has the possibility to form two hydrogen bonds as an acceptor and two hydrogen bonds as a donor. From the data presented in Table 1 it is clear that the interaction with carboxylic acids is significantly more favourable than all other interactions. Hence we will in the following section focus mainly on the ability of various common atmospheric carboxylic acids to bind to sulfuric acid.

\subsection{Interaction between $\mathrm{H}_{2} \mathrm{SO}_{4}$ and Atmospheric Carboxylic Acids}

As shown in the previous section, carboxylic acids are the most promising candidate functional group to be involved in cluster formation with sulfuric acid. To further investigate what governs the binding strength between different carboxylic acids and sulfuric acid, we have chosen a range of acids (acetic, benzoic, ethylperoxy, formic, maleic, malic, mal-

onic, methylperoxy, oxalic, phenylacetic, phthalic, pyruvic, succinic and tartaric). These compounds represent some of the most abundant carboxylic acids identified in ambient aerosols ${ }^{60-69}$ and their structures can be seen in Figure 1. This test set thereby comprise of carboxylic acids with varied moieties such as mono/di-carboxylic acids, as well as peroxy acids to also reflect the molecular structure of products formed via autoxidation. 


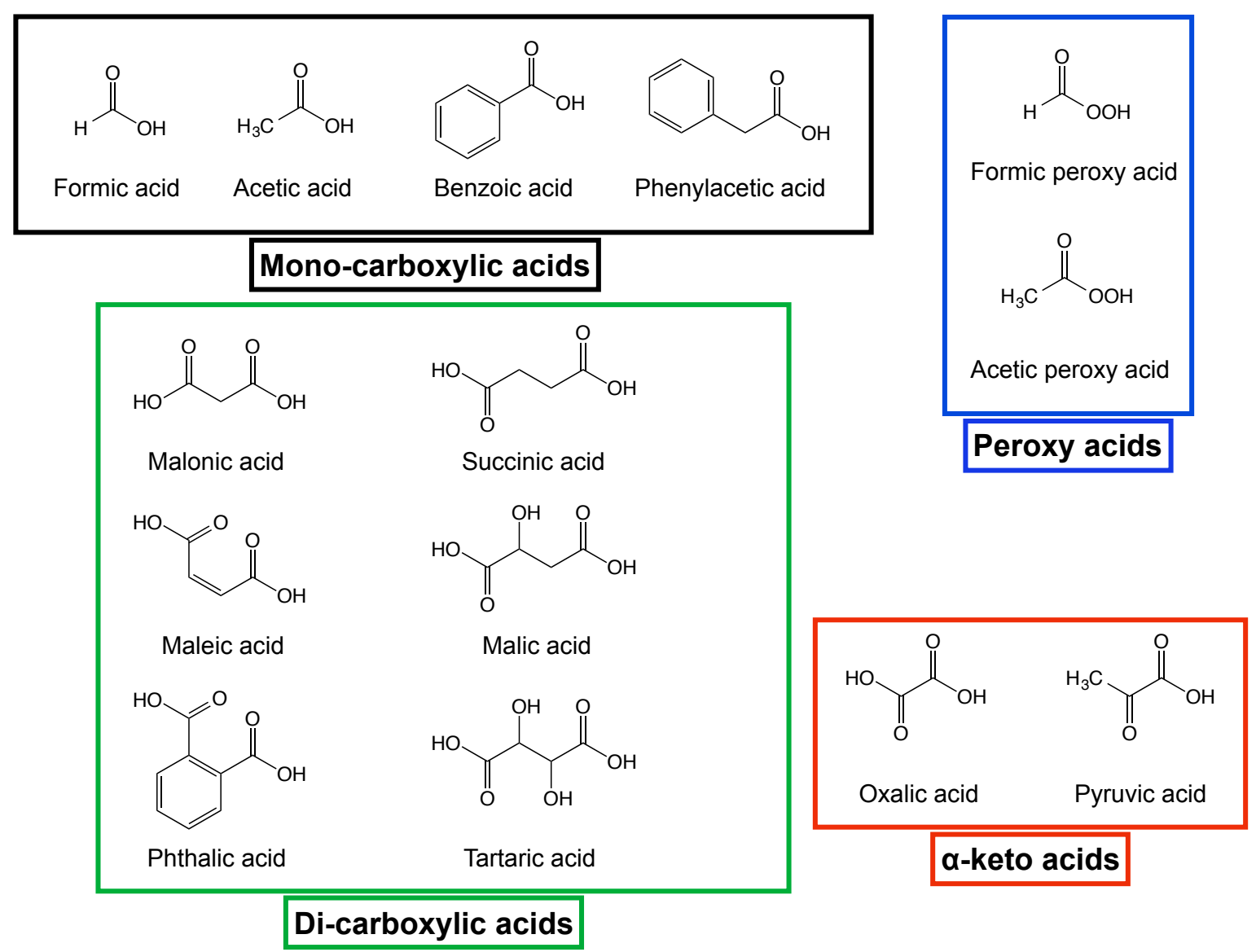

Figure 1: Model compounds.

Due to the larger size of the clusters compared to previous section, we utilize CCSD(T)F12a/VDZ-F12 to calculate the binding energies. By applying the semi-empirically guided sampling technique, outlined in section 2.1, several conformations were identified for each $\left(\mathrm{H}_{2} \mathrm{SO}_{4}\right)$ (acid) cluster. We identified up to 33 different conformations in case of the $\left(\mathrm{H}_{2} \mathrm{SO}_{4}\right)$ (succinic acid) cluster, within $6 \mathrm{kcal} / \mathrm{mol}$ of the lowest free energy structure. In case of malonic acid, oxalic acid, and succinic acid, the three functionals did not unambiguously identify the same cluster as the lowest in Gibbs free energy and all the different minima were subsequently used when evaluating the CCSD(T)-F12a/VDZ-F12 coupled cluster binding energy. The identified lowest Gibbs free energy molecular structures of the sulfuric acid - organic acid clusters are presented in Figure 2. 


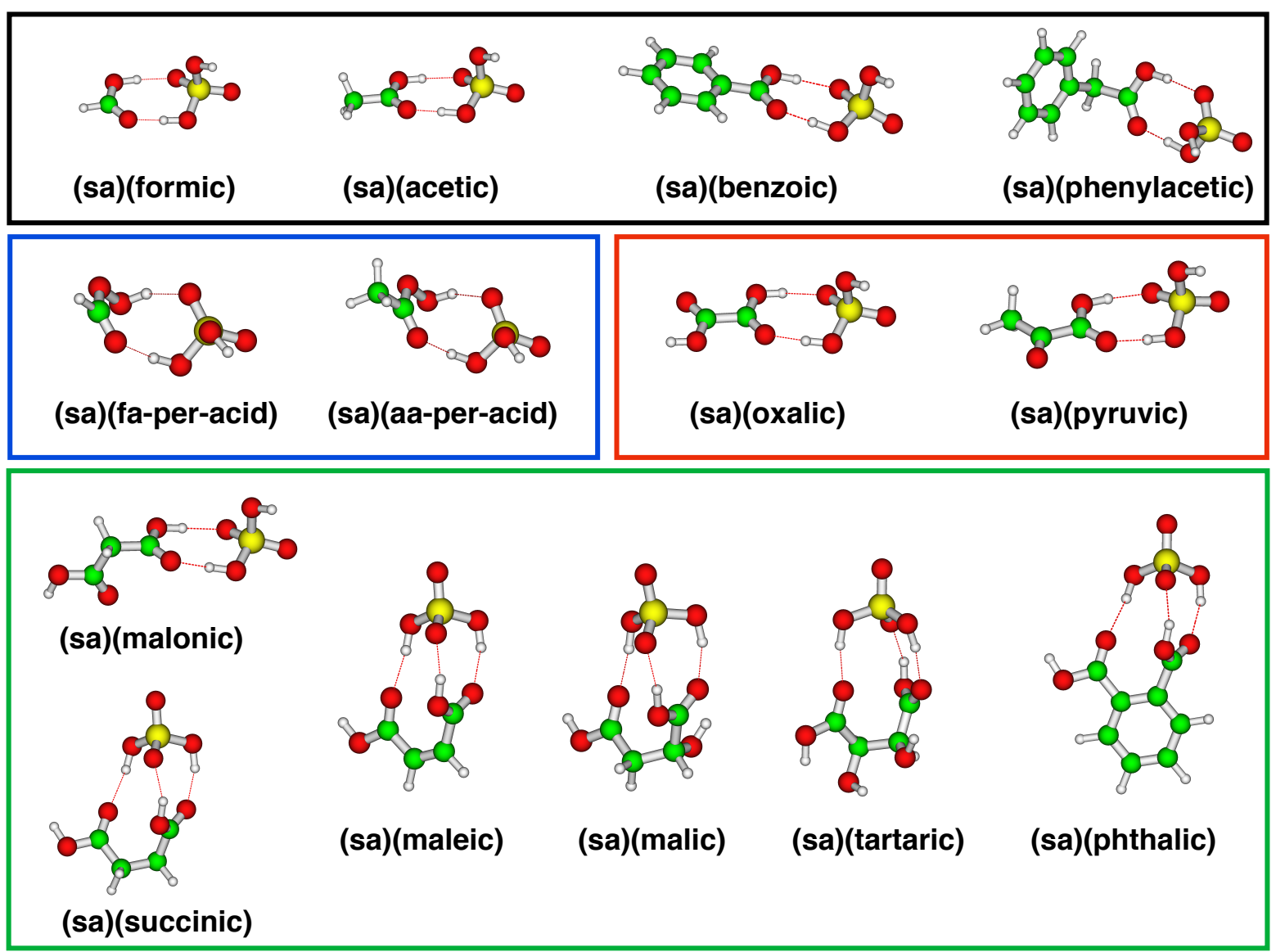

Figure 2: Lowest Gibbs free energy molecular structures of the sulfuric acid - organic acid clusters. The clusters shown are based on the M06-2X/6-31++G(d,p) calculations. Green $=$ carbon, red $=$ oxygen, yellow $=$ sulfur and white $=$ hydrogen .

The calculated average reaction free energies are shown in Table 2. The corresponding reaction free energies calculated using the individual functionals with a $6-31++\mathrm{G}(\mathrm{d}, \mathrm{p})$ basis set are shown in the supporting information. For each functional the lowest Gibbs free energy structure is used, i.e. the values might originate from slightly different conformations in the case of malonic acid, oxalic acid, and succinic acid. $\Delta G_{3 \text {-H-bond }}$ refers to the lowest free energy structure obtained, where three hydrogen bonds are present. $\Delta G_{2 \text {-H-bond }}$ refers to the lowest free energy structure where sulfuric acid only interacts with the carboxylic acid group via two hydrogen bonds and does not make any additional hydrogen bonds via its remaining $\mathrm{S}-\mathrm{OH}$ group. The standard deviation $(\sigma)$ is reported in the parenthesis. The reaction free energies for forming the $\left(\mathrm{H}_{2} \mathrm{SO}_{4}\right)_{2},\left(\mathrm{H}_{2} \mathrm{SO}_{4}\right)\left(\mathrm{NH}_{3}\right)$ and $\left(\mathrm{H}_{2} \mathrm{SO}_{4}\right)\left(\left(\mathrm{CH}_{3}\right)_{2} \mathrm{NH}\right)$ clusters have previously been reported at the same level of theory ${ }^{70}$ and are also shown as a comparison. 
Table 2: Calculated average reaction free energies for forming sulfuric acid - organic acid clusters. The binding energy is calculated at the CCSD(T)-F12a/VDZ-F12 level of theory on top of each of the DFT/6-31++G(d,p) structures. $\Delta G_{2 \text {-H-bond }}$ and $\Delta G_{3-H-b o n d}$ refers to the lowest free energy structures, where sulfuric acid forms either two or three hydrogen bonds to the organic acid. The standard deviation $(\sigma)$ is reported in the parenthesis. Calculations were performed at $298.15 \mathrm{~K}$ and $1 \mathrm{~atm}$ and all values are presented in $\mathrm{kcal} / \mathrm{mol}$.

\begin{tabular}{|c|c|c|}
\hline Method & $\Delta G_{2 \text {-H-bond }}$ & $\Delta G_{3-\mathrm{H}-\mathrm{bon}}$ \\
\hline \multicolumn{3}{|l|}{ Dicarboxylic acids } \\
\hline Phthalic acid & $-4.9(0.2)$ & $-8.8(0.1)$ \\
\hline Malic acid & $-6.2(0.1)$ & $-8.1(0.2)$ \\
\hline Tartaric acid & $-6.0(0.3)$ & $-7.7(0.6)$ \\
\hline Succinic acid & $-6.8(0.2)$ & $-6.8(0.9)$ \\
\hline Maleic acid & $-6.6(0.6)$ & $-6.7(0.1)$ \\
\hline Malonic acid & $-6.0(0.3)$ & $-5.4(0.1)$ \\
\hline \multicolumn{3}{|l|}{$\underline{\alpha \text {-keto acids }}$} \\
\hline Oxalic acid & $-1.6(0.1)$ & - \\
\hline Pyruvic acid & $-2.3(0.2)$ & - \\
\hline \multicolumn{3}{|l|}{ Peroxy acids } \\
\hline Formic peroxy acid & $-1.2(0.2)$ & - \\
\hline Acetic peroxy acid & $-1.9(0.4)$ & - \\
\hline \multicolumn{3}{|c|}{ Monocarboxylic acids } \\
\hline Benzoic acid & $-6.9(0.1)$ & - \\
\hline Phenylacetic acid & $-6.1(0.3)$ & - \\
\hline Formic acid & $-5.4(0.1)$ & - \\
\hline Acetic acid & $-6.6(0.4)$ & - \\
\hline$\left(\mathrm{H}_{2} \mathrm{SO}_{4}\right)_{2}$ & $-6.0(0.2)^{70}$ & \\
\hline$\left(\mathrm{H}_{2} \mathrm{SO}_{4}\right)\left(\mathrm{NH}_{3}\right)$ & $-5.2(0.2)^{70}$ & \\
\hline$\left(\mathrm{H}_{2} \mathrm{SO}_{4}\right)\left(\left(\mathrm{CH}_{3}\right)_{2} \mathrm{NH}\right)$ & $-11.9(0.9)^{70}$ & \\
\hline
\end{tabular}


Oxalic acid shows a very weak interaction with sulfuric acid $(\Delta G=-1.6 \mathrm{kcal} / \mathrm{mol})$. A similarly weak binding is observed for pyruvic acid with a $\Delta G$-value of $-2.3 \mathrm{kcal} / \mathrm{mol}$. These low values can be understood from the increased stability of the isolated oxalic acid and pyruvic acid molecules, where it is possible to form an intramolecular hydrogen bond from the acid group to the adjacent $\alpha$-carbonyl group (see supporting information for structures). The reaction free energy is significantly enhanced by increasing the number of carbon atoms between the two acid moieties, as seen in malonic acid $(\Delta G=-6.0 \mathrm{kcal} / \mathrm{mol})$ and succinic acid $(\Delta G=-6.8 \mathrm{kcal} / \mathrm{mol})$ compared to oxalic acid $(\Delta G=-1.6 \mathrm{kcal} / \mathrm{mol})$. Peroxy formic acid and peroxy acetic acid both yield weak formation free energies of $-1.2 \mathrm{kcal} / \mathrm{mol}$ and $-1.9 \mathrm{kcal} / \mathrm{mol}$, respectively. As discussed in section 3.1 this weak interaction also originates from the intramolecular hydrogen bond from the peroxy acids - $\mathrm{OOH}$ group to its own $\mathrm{C}=\mathrm{O}$ group. For formic acid we obtain a reaction free energy value of $-5.4 \mathrm{kcal} / \mathrm{mol}$. This is slightly less favourable than the formation of the sulfuric acid dimer $(\Delta G=-6.0 \mathrm{kcal} / \mathrm{mol})$, but of similar magnitude as the sulfuric acid - ammonia cluster with a reaction free energy of $\Delta G=-5.2 \mathrm{kcal} / \mathrm{mol}$. A slightly more favourable value $(\Delta G=-6.6 \mathrm{kcal} / \mathrm{mol})$ is obtained for acetic acid. The fact that formic acid forms a weaker interaction with sulfuric acid compared to acetic acid, despite having a lower $\mathrm{pK}_{a}$-value, suggests that the carboxylic acid strength does not directly correlate with its ability to form clusters with sulfuric acid. This difference is both a consequence of a difference in the thermal contribution and the binding energy. Formic acid has an average binding energy of $-17.5 \mathrm{kcal} / \mathrm{mol}$, with a thermal contribution of $12.1 \mathrm{kcal} / \mathrm{mol}$. For acetic acid both the binding energy and thermal contributions are both slightly lower with $\Delta E=-18.3 \mathrm{kcal} / \mathrm{mol}$, and $\Delta G_{\text {Thermal }}=11.7 \mathrm{kcal} / \mathrm{mol}$.

The most favourable reaction free energies are found in the clusters where it is possible to form an additional hydrogen bond from the $\mathrm{S}-\mathrm{OH}$ group in sulfuric acid to an available $\gamma$-carbonyl group in the carboxylic acid (phthalic -, malic -, maleic -, tartaric -, and succinic acid). 
In $\beta$-carbonyl acids, such as malonic acid, the formation of the third hydrogen bond leads to a slight destabilization compared to the conformation which only form two hydrogen bonds, caused by the higher strain in the molecular backbone. The stabilizing effect of

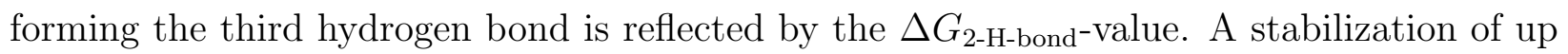
to $3.9 \mathrm{kcal} / \mathrm{mol}$ is observed for forming the additional hydrogen bond in case of phthalic acid. This clearly indicates that the strength of the interaction between sulfuric acid and a carboxylic acid is directly related to the ability of sulfuric acid to form the additional hydrogen bond. Furthermore, having a hydroxyl group (-OH) attached at the $\alpha$-carbon is able to stabilize the complex formation with sulfuric acid as reflected by the favourable reaction free energies of malic acid $(\Delta G=-8.1 \mathrm{kcal} / \mathrm{mol})$ and tartaric acid $(\Delta G=-7.7$ $\mathrm{kcal} / \mathrm{mol})$ compared to succinic acid $(\Delta G=-6.8 \mathrm{kcal} / \mathrm{mol})$.

The extra formed hydrogen bond will lead to a more favourable binding energy, but also a higher thermal contribution, as the cluster is being more constrained. Phthalic, malic, tartaric, succinic and maleic acid have thermal contributions in the range of 13.4$15.2 \mathrm{kcal} / \mathrm{mol}$ (maleic- and phthalic acid, respectively). This is slightly higher than the remaining acids which lies in the range of 11.1-12.5 kcal/mol (oxalic- and phenylacetic acid, respectively). We find that tartaric-, phthalic- and malic acid has the lowest average binding energies of $-22.9,-22.7$ and $-21.9 \mathrm{kcal} / \mathrm{mol}$, respectively. This is significantly more favourable than the monocarboxylic acids, where the average binding energies are in the range of -17.5 to $-18.7 \mathrm{kcal} / \mathrm{mol}$ for formic acid and benzoic acid, respectively.

In the following we will extend the analysis to the interaction between sulfuric acid and carboxylic acids originating from $\alpha$-pinene oxidation to identify whether these trends apply for larger systems as well.

\subsection{Clustering of $\mathrm{H}_{2} \mathrm{SO}_{4}$ and Monoterpene Markers}

To study larger clusters than those studied in previous section the CCSD(T)-F12a/VDZ-F12 method is out of reach and we will employ the DLPNO-CCSD(T) method instead. Using 
the CCSD(T)-F12a/VDZ-F12 binding energy calculations of the organic acids (Figure 1) as a benchmark set we assess the performance DLPNO-CCSD $(\mathrm{T})$ using the cc-pVXZ $(\mathrm{X}=$ $\mathrm{D}, \mathrm{T}, \mathrm{Q})$, aug-cc-pVXZ $(\mathrm{X}=\mathrm{D}, \mathrm{T})$ and Def2-QZVPP basis sets as shown in Table S5 in the Supporting Information. The Def2-QZVPP basis set, which we have previously used in connection with the DLPNO method for studying the interaction between sulfuric acid and highly oxidized organic compounds, ${ }^{19,20,71}$ yield a large MAE of $1.1 \mathrm{kcal} / \mathrm{mol}$, with a MaxE of $1.8 \mathrm{kcal} / \mathrm{mol}$. This discrepancy is caused due to a large underestimation of the binding energy (i.e. less negative). Using the Def2-QZVPP basis set practically yield the same performance as the smaller aug-cc-pVDZ. We find that DLPNO-CCSD(T)/aug-cc-pVTZ yield a good agreement with the CCSD(T)-F12a/VDZ-F12 results, with a mean absolute error (MAE) of $0.2 \mathrm{kcal} / \mathrm{mol}$ and a maximum error of $0.8 \mathrm{kcal} / \mathrm{mol}$. This is in good agreement with previous benchmark calculations on atmospheric mono/diamines ${ }^{70}$ as well as a test set of 11 atmospheric cluster reactions. ${ }^{53}$ Hence we will use DLPNO-CCSD(T)/aug-cc-pVTZ for calculations on larger sulfuric acid - carboxylic acid clusters.

We calculate the reaction free energy of sulfuric acid clustering with the common monoterpene markers: pinic acid, ${ }^{72-76}$ 3-methyl-1,2,3-butanetricarboxylic acid (MBTCA), ${ }^{77,78}$ terebic acid, ${ }^{79-81}$ 3-hydroxy glutaric acid ${ }^{79,82}$ and terpenylic acid. ${ }^{79-81,83}$ The pinic acid and MBTCA cluster structures have been taken from previous studies. ${ }^{59,84}$ It should be noted that we use the monomer of pinic acid as identified in reference, ${ }^{85}$ as it is $1.0 \mathrm{kcal} / \mathrm{mol}$ more stable than the identified global minimum energy conformer in our original paper. ${ }^{59}$ The 3hydroxy-glutaric acid, terebic acid and terpenylic acid cluster structures have been identified using the same semi-empirically guided sampling technique as outlined in section 2.1. The identified molecular structures which were found to be lowest in free energy are presented in Figure 3 and the corresponding reaction free energies are presented in Table 3. 


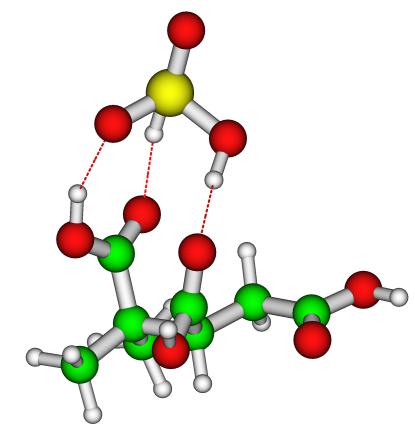

(sa)(MBTCA)

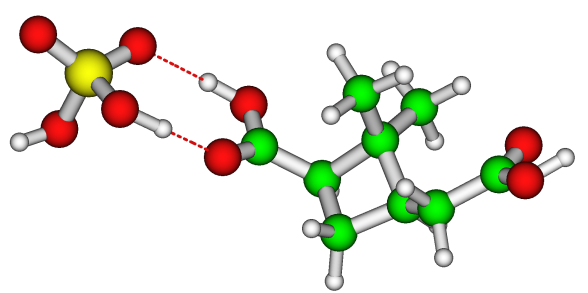

(sa)(pinic)

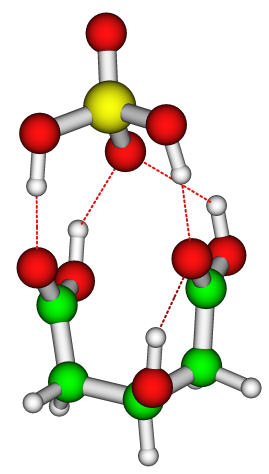

(sa)(3-OH-glutaric)

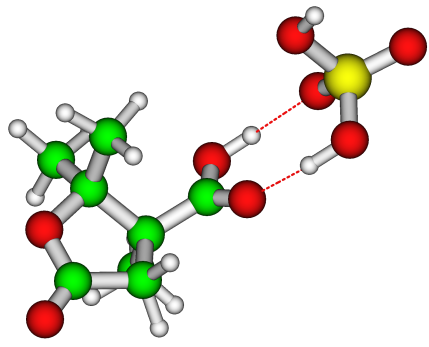

(sa)(terebic)

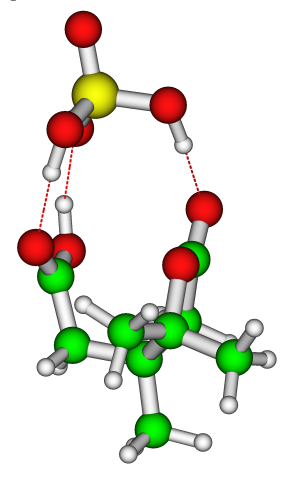

(sa)(terpenylic)

Figure 3: Lowest free energy molecular structure of sulfuric acid (sa) clustering with MBTCA, pinic-, 3-hydroxy glutaric-, terebic- and terpenylic acid. The clusters shown are based on the M06-2X/6-31++G(d,p) calculations

The $\left(\mathrm{H}_{2} \mathrm{SO}_{4}\right)$ (pinic) and $\left(\mathrm{H}_{2} \mathrm{SO}_{4}\right)$ (terebic) clusters are only able to form two hydrogen bonds with sulfuric acid, where the remaining clusters are able to also form an additional bond via the vacant S-OH group in sulfuric acid to a carbonyl group in the carboxylic acid. Interestingly, 3-hydroxy-glutaric acid shows a very weak interaction $(\Delta G=-6.0 \mathrm{kcal} / \mathrm{mol})$ with sulfuric acid, despite forming additional hydrogen bonds. This is most likely a consequence of the $\mathrm{OH}$ group residing on the $\beta$-carbon instead of the $\alpha$-carbon in case of malicand tartaric acid. Additionally, the high strain in the carbon backbone required to form the additional hydrogen bonds could also contribute to the higher reaction free energy. The reaction free energy for forming the terebic acid - sulfuric acid cluster is found to be -6.1 $\mathrm{kcal} / \mathrm{mol}$. MBTCA and pinic acid show a slightly stronger interaction, with reaction free 
energies of $-7.5 \mathrm{kcal} / \mathrm{mol}$ and $-6.4 \mathrm{kcal} / \mathrm{mol}$, respectively. Terpenylic acid shows the strongest interaction with sulfuric acid, with a reaction free energy of $-9.1 \mathrm{kcal} / \mathrm{mol}$. The reaction free energy of the monoterpene markers only varies from $-6.0 \mathrm{kcal} / \mathrm{mol}$ to $-9.1 \mathrm{kcal} / \mathrm{mol}$, which, similarly to section 3.2, suggests that the interaction between sulfuric acid and carboxylic acids is not very dependent on the backbone of the carboxylic acid. To further look into this aspect, we calculated the lowest free energy structure where sulfuric acid only interacts with the carboxylic acid group ( $\left.\Delta G_{2-\mathrm{H}-b o n d}\right)$ and do not form any additional hydrogen bonds via its remaining $\mathrm{S}-\mathrm{OH}$ group. In Table 3 it is seen that the direct interactions do not vary significantly from each other with $\Delta G_{2-\mathrm{H}-b o n d}$-values in the range of $-6.4 \mathrm{kcal} / \mathrm{mol}$ to -5.5 $\mathrm{kcal} / \mathrm{mol}$. By looking into the individual contributions to the free energy we find that pinic acid and terebic acid, which only form two hydrogen bonds to sulfuric acid, have the lowest thermal contributions with a value of $12.0 \mathrm{kcal} / \mathrm{mol}$ in both cases. MBTCA, terpenylic-, and 3-OH-glutaric acid all form an additional hydrogen bond, leading to a higher thermal contribution of $14.7,15.6$ and $16.5 \mathrm{kcal} / \mathrm{mol}$. These values are slightly higher than the smaller dicarboxylic acids in section 3.2, where values in the range 13.4-15.2 kcal/mol was identified.

Table 3: Calculated average reaction free energies for sulfuric acid clustering with monoterpene markers. The binding energy is calculated at the DLPNO-CCSD(T)/aug-cc-pVTZ level of theory on top of each of the DFT/6-31++G(d,p) structures. The standard deviation $(\sigma)$ is reported in the parenthesis. The calculations are performed at $298.15 \mathrm{~K}$ and $1 \mathrm{~atm}$ and all values are presented in $\mathrm{kcal} / \mathrm{mol}$.

\begin{tabular}{lcc}
\hline \hline Method & $\Delta G_{\text {3-H-bond }}$ & $\Delta G_{\text {2-H-bond }}$ \\
\hline \hline Pinic acid & - & $-6.4(0.2)$ \\
Terebic acid & - & $-6.1(0.1)$ \\
Terpenylic acid & $-9.1(0.4)$ & $-5.5(0.4)$ \\
MBTCA & $-7.5(0.2)$ & $-6.3(0.3)$ \\
3-hydroxy-glutaric acid & $-6.0(0.3)$ & $-5.7(0.2)$
\end{tabular}

This finding clearly illustrates that the cluster reaction free energy only depends on the carboxylic acids ability to form additional hydrogen bonds. 


\subsection{Clustering of $\mathrm{H}_{2} \mathrm{SO}_{4}$ with a Large Dimer Ester}

None of the investigated carboxylic acids binds nearly as strong to sulfuric acid as dimethylamine $(\Delta G \approx-12 \mathrm{kcal} / \mathrm{mol})$. It appears that all the $\Delta G_{2 \text {-H-bond-values are more or less }}$ independent of the backbone of the carboxylic acid (excluding the peroxy- and $\alpha$-keto acids) with values of $\Delta G \approx-6 \mathrm{kcal} / \mathrm{mol}$ in all cases. The sulfuric acid molecule has two hydrogen bond donors and two hydrogen bond acceptors, hence assuming no synergetic effects, implying that the available hydrogen bonded interactions can simply be added, the highest possible free energy would then arise from two carboxylic acids in the same molecule interacting with sulfuric acid, for a total of $\Delta G \approx-12 \mathrm{kcal} / \mathrm{mol}$. Currently, the only molecular species possibly present in the atmosphere which could fulfill the requirement of simultaneously interacting with sulfuric acid via two carboxylic acid groups, are large molecular weight dimers with two or more carboxylic acids moieties. One of the simplest dimer compounds proposed in the literature is the dimer ester formed from two pinic acid subunits in the form of the pinonyl-pinyl ester. ${ }^{86,87}$

Large dimer esters present a significant computational challenge, as it is difficult to systematically sample the configurational space of even the monomers. A slightly different approach was thereby utilized to identify the global minimum structure of the pinonylpinyl ester. Initially 30 guess structures were generated using a series of weighted rotor searches in Avogadro. Hence each subsequent search used the best estimate from the previous search. The weighted rotor approach is to some extend similar to Monte Carlo sampling. We also included several manually sampled structures, based on chemical intuition, to further evaluate the configurational space. All the structures were then geometry optimized and frequencies were calculated at the M06-2X/6-31++G(d,p) level of theory. The two best candidate structures (lowest in free energy) were then used as a starting point for a Born-Oppenheimer Molecular Dynamics (BOMD) simulation using the semiempirical PM6 method. For both starting conformations a trajectory of 3.5 ps was computed at 298.15 K using 10000 timesteps and otherwise default criteria in Gaussian. Along each trajectory 
20 structures were extracted in even intervals and subsequently also optimized at the M06$2 \mathrm{X} / 6-31++\mathrm{G}(\mathrm{d}, \mathrm{p})$ level of theory. The cluster between pinonyl-pinyl ester and sulfuric acid was only manually sampled. The identified structures lowest in free energy can be seen in Figure 4, calculated at the M06-2X/6-31++G(d,p) level of theory.

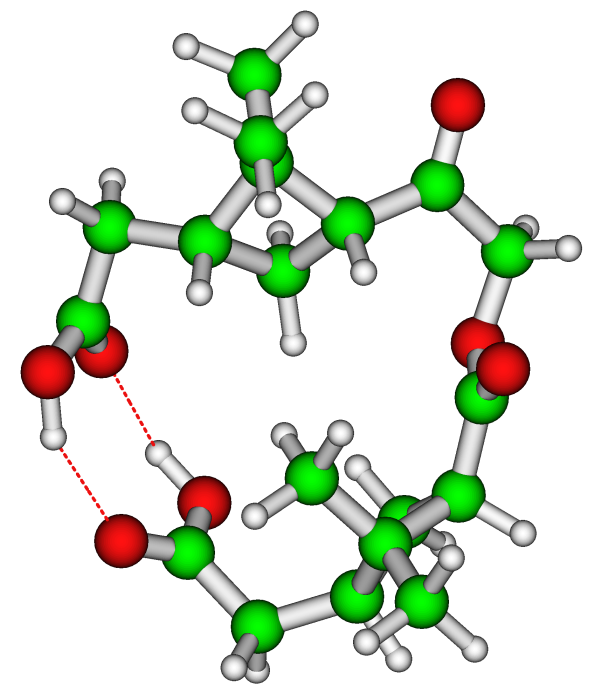

pinonyl-pinyl ester (ppe)

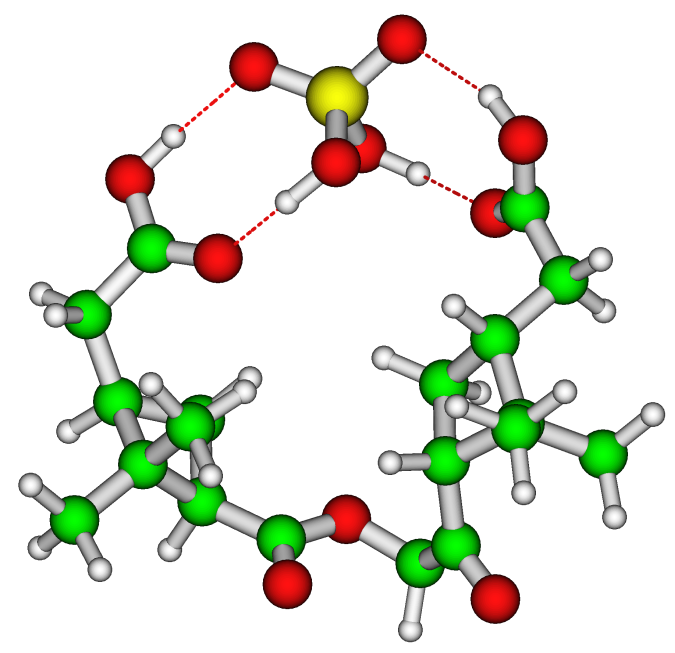

(sa)(ppe)

Figure 4: Lowest free energy molecular structure of a pinonyl-pinyl ester (ppe) (left) and its clustering with sulfuric acid (right). The shown structures are based on the M06-2X/6$31++\mathrm{G}(\mathrm{d}, \mathrm{p})$ calculation.

The lowest free energy structure of the pinonyl-pinyl ester is seen to have intramolecular hydrogen bonded interactions between its two peripheral carboxylic acid groups. Similarly, to the previous studied compounds in section 3.2-3.3, this leads to a stabilization of the monomer. However, as the hydrogen bonds are not able to reach the most favourable coplaner orientation, the stabilization should be significantly lower than that of a direct carboxylic acid - carboxylic acid interaction. The cluster formation with sulfuric acid, thereby 
needs to break the intramolecular hydrogen bonds to form the cluster. The resulting interaction between sulfuric acid is seen to yield almost co-planar hydrogen bonds, leading to a favourable interaction. At the DLPNO-CCSD(T)/aug-cc-pVTZ//DFT/6-31++G(d,p) level of theory, we obtain an average cluster reaction free energy of $-9.1 \mathrm{kcal} / \mathrm{mol}$, with $\sigma=0.4$ $\mathrm{kcal} / \mathrm{mol}$. The large pinonyl-pinyl dimer ester thereby has the same magnitude in reaction free energy as the interaction between sulfuric acid and terpenylic acid. This further illustrates that intramolecular hydrogen bonding can significantly hinder the ability of a given organic oxidation product to form stable clusters with sulfuric acid. As we have only manually constructed the sulfuric acid - pinonyl-pinyl ester cluster, we cannot exclude that a lower free energy conformation exists. Furthermore, as the pinic acid molecule has two different acid groups, three different pinonyl-pinyl ester structures could exist and we have only taken one of them into account here. The thermal contribution to the free energy for the pinonyl-pinyl ester is found to be $12.4 \mathrm{kcal} / \mathrm{mol}$, with $\sigma=0.6 \mathrm{kcal} / \mathrm{mol}$. This value is very similar to the values found for the small systems investigated in section 3.1. This shows that even these large dimer esters do not show a significantly higher thermal contribution than the smaller molecules and the free energy value is hence limited by a weak binding energy, as well as the stabilization of the monomer via intramolecular hydrogen bonds.

Combined our finding presented herein suggests that in order for a HOM to participate in the initial steps in new particle formation, several specific molecular traits should be present in the reacting monomer:

- Either weak or no intramolecular hydrogen bonds.

- At least two direct sulfuric acid - carboxylic acid interactions.

These requirements represents the "docking" of the sulfuric acid molecule in-between the two carboxylic acid groups in a large dicarboxylic acid. This type of interaction will allow for the sulfuric acid molecule to form nearly co-planar hydrogen bonds to the two carboxylic acid groups, leading to a favourable interaction. Under ideal circumstances, these two require- 
ments would then allow for the formation of a stable (sulfuric acid)(HOM) cluster. Figure 5 show an example of how the cluster structure could look like fulfilling these requirements.
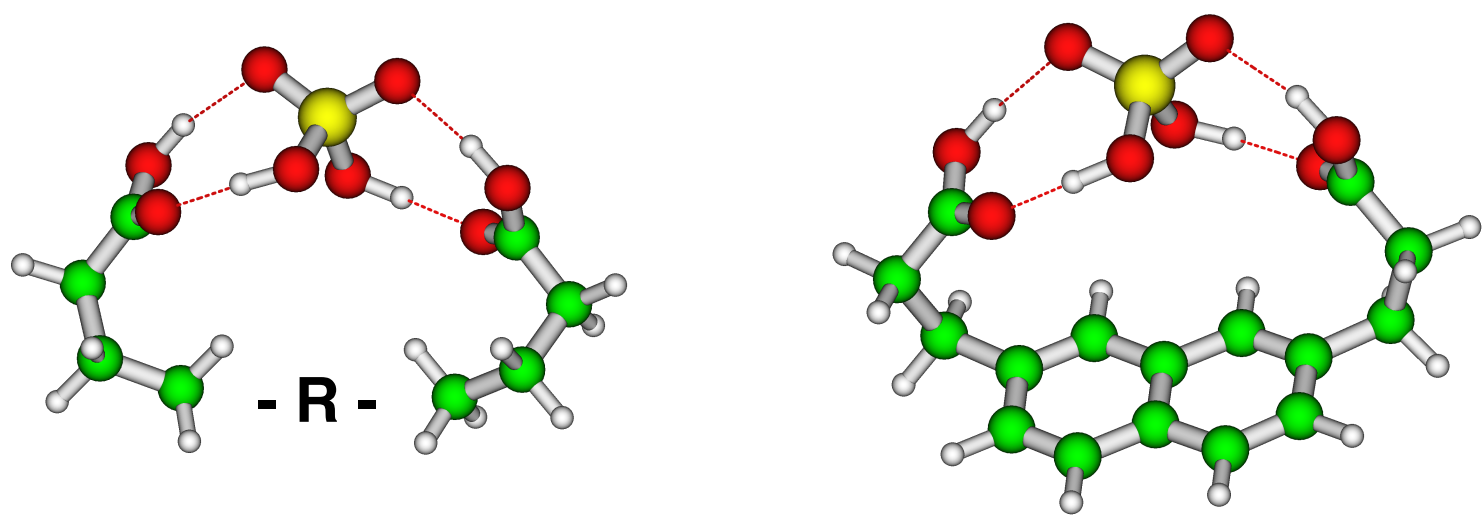

Figure 5: (Left) Schematic of the ideal situation for forming a strong (sa)(HOM) complex. The - R - group represents any type of backbone which connect the two carboxylic acid groups. (Right) structure in the case where naphthalene is chosen as the linker

Here the - R - group represents any potential linker which connects the two carboxylic acid groups. As a model system we tested naphthalene as the linker group (see Figure 5) and obtained an average reaction free energy of $-15.1 \mathrm{kcal} / \mathrm{mol}$, with $\sigma=0.8 \mathrm{kcal} / \mathrm{mol}$ at the DLPNO-CCSD $(\mathrm{T}) /$ aug-cc-pVTZ//DFT/6-31++G(d,p) level of theory. Partitioning this value into its energy and thermal contribution to the free energy, we find an average binding energy of $-34.3 \mathrm{kcal} / \mathrm{mol}$, with $\sigma=0.5 \mathrm{kcal} / \mathrm{mol}$ and the average thermal contribution is $19.3 \mathrm{kcal} / \mathrm{mol}$, with $\sigma=1.2 \mathrm{kcal} / \mathrm{mol}$. The $\Delta G$-value of $-15.1 \mathrm{kcal} / \mathrm{mol}$ represents the best case scenario obtainable, as atmospherically relevant systems originating from monoterpene oxidation most likely will not have an ideal linker between the two carboxylic acid groups.

\section{Conclusions}

We have studied the molecular interaction between sulfuric acid and oxidized organic compounds to elucidate the requirements for a given molecule to efficiently stabilize sulfuric acid clustering. Starting from simple functional groups we find that carboxylic acid groups show 
the strongest interaction with sulfuric acid and narrow the potential molecular features of the given organic compound to the following two distinct properties:

- Weak or no intramolecular hydrogen bonds in the monomer.

- At least two direct sulfuric acid - carboxylic acid interactions.

Additionally, more than two carboxylic acid groups might be required to enable further growth. We test these two specific requirements using a proxy compound and estimates a lower limit for this type of interaction to be $-15.1 \mathrm{kcal} / \mathrm{mol}$. This interaction is more favourable than the corresponding interaction between sulfuric acid and dimethylamine, suggesting that highly oxidized organic compounds fulfilling all the three criteria might be able to efficiently stabilize sulfuric acid clusters. Whether such compounds actually exist in the atmosphere remains unknown. Based on our results, the most promising candidates are likely to be high-molecular weight compounds formed in oligomerization reactions of two or more terpene oxidation products.

\section{Acknowledgement}

J.E thanks the Carlsberg foundation for financial support. We thank the Academy of Finland and ERC project 692891-DAMOCLES for funding and the CSC-IT Center for Science in Espoo, Finland, for computational resources.

\section{Supporting Information Available}

Cartesian coordinates as xyz-files and the calculated formation free energies are available as supporting information. This material is available free of charge via the Internet at http://pubs.acs.org/. 


\section{References}

(1) Kulmala, M.; Kontkanen, J.; Junninen, H.; Lehtipalo, K.; Manninen, H. E.; Nieminen, T.; Petäjä, T.; Sipilä, M.; Schobesberger, S.; Rantala, P. et al. Direct Observations of Atmospheric Aerosol Nucleation. Science 2013, 339, 943-946.

(2) Merikanto, J.; Spracklen, D. V.; Mann, G. W.; Pickering, S. J.; Carslaw, K. S. Impact of Nucleation on Global CCN. Atmos. Chem. Phys. 2009, 9, 8601-8616.

(3) O’Dowd, C. D.; Jimenez, J. L.; Bahreini, R.; Flagan, R. C.; Seinfeld, J. H.; Hämeri, K.; Pirjola, L.; Kulmala, M.; Jennings, S. G.; Hoffmann, T. Marine Aerosol Formation from Biogenic Iodine Emissions. Nature 2002, 417.

(4) Sipilä, M.; Sarnela, N.; Jokinen, T.; Henschel, H.; Junninen, H.; Kontkanen, J.; Richters, S.; Kangasluoma, J.; Franchin, A.; Perkyl, O. et al. Molecular-scale Evidence of Aerosol Particle Formation via Sequential Addition of $\mathrm{HIO}_{3}$. Nature 2016 , $537,532-534$.

(5) Sipilä, M.; Berndt, T.; Petäjä, T.; Brus, D.; Vanhanen, J.; Stratmann, F.; Patokoski, J.; Mauldin, R. L.; Hyvrinen, A.-P.; Lihavainen, H. et al. The Role of Sulfuric Acid in Atmospheric Nucleation. Science 2010, 327, 1243-1246.

(6) Almeida, J.; Schobesberger, S.; Kurten, A.; Ortega, I. K.; Kupiainen-Maatta, O.; Praplan, A. P.; Adamov, A.; Amorim, A.; Bianchi, F.; Breitenlechner, M. et al. Molecular Understanding of Sulphuric Acid-Amine Particle Nucleation in the Atmosphere. Nature 2013, 502, 359-363.

(7) Zhang, R.; Suh, I.; Zhao, J.; Zhang, D.; Fortner, E. C.; Tie, X.; Molina, L. T.; Molina, M. J. Atmospheric New Particle Formation Enhanced by Organic Acids. Science 2004, 304, 1487-1490. 
(8) Schobesberger, S.; Junninen, H.; Bianchi, F.; Lönn, G.; Ehn, M.; Lehtipalo, K.; Dommen, J.; Ehrhart, S.; Ortega, I. K.; Franchin, A. et al. Molecular Understanding of Atmospheric Particle Formation from Sulfuric Acid and Large Oxidized Organic Molecules. Proc. Natl. Acad. Sci. U.S.A. 2013, 110, 17223-17228.

(9) Riccobono, F.; Schobesberger, S.; Scott, C. E.; Dommen, J.; Ortega, I. K.; Rondo, L.; Almeida, J.; Amorim, A.; Bianchi, F.; Breitenlechner, M. et al. Oxidation Products of Biogenic Emissions Contribute to Nucleation of Atmospheric Particles. Science 2014, $344,717-721$.

(10) Ehn, M.; Thornton, J. A.; Kleist, E.; Sipilä, M.; Junninen, H.; Pullinen, I.; Springer, M.; Rubach, F.; Tillmann, R.; Lee, B. et al. A Large Source of Low-Volatility Secondary Organic Aerosol. Nature 2014, 506, 476-479.

(11) Rissanen, M. P.; Kurtén, T.; Sipilä, M.; Thornton, J. A.; Kangasluoma, J.; Sarnela, N.; Junninen, H.; Jørgensen, S.; Schallhart, S.; Kajos, M. K. et al. The Formation of Highly Oxidized Multifunctional Products in the Ozonolysis of Cyclohexene. J. Am. Chem. Soc. 2014, 136, 15596-15606.

(12) Rissanen, M. P.; Kurtén, T.; Sipilä, M.; Thornton, J. A.; Kausiala, O.; Garmash, O.; Kjaergaard, H. G.; Petäjä, T.; Worsnop, D. R.; Ehn, M. et al. Effects of Chemical Complexity on the Autoxidation Mechanisms of Endocyclic Alkene Ozonolysis Products: From Methylcyclohexenes toward Understanding aPinene. J. Phys. Chem. A 2015, 119, 4633-4650.

(13) Crounse, J. D.; Nielsen, L. B.; Jørgensen, S.; Kjaergaard, H. G.; Wennberg, P. O. Autoxidation of Organic Compounds in the Atmosphere. J. Phys. Chem. Lett. 2013, 4, 3513-3520.

(14) Jokinen, T.; Sipilä, M.; Richters, S.; Kerminen, V.; Paasonen, P.; Stratmann, F.; Worsnop, D.; Kulmala, M.; Ehn, M.; Herrmann, H. et al. Rapid Autoxidation Forms 
Highly Oxidized RO2 Radicals in the Atmosphere. Angew. Chem. Int. Ed. 2014, 53, $14596-14600$.

(15) Jokinen, T.; Berndt, T.; Makkonen, R.; Kerminen, V.-M.; Junninen, H.; Paasonen, P.; Stratmann, F.; Herrmann, H.; Guenther, A. B.; Worsnop, D. R. et al. Production of Extremely Low Volatile Organic Compounds from Biogenic Emissions: Measured Yields and Atmospheric Implications. Proc. Natl. Acad. Sci. U.S.A. 2015, 112, 7123-7128.

(16) Berndt, T.; Richters, S.; Kaethner, R.; Voigtlnder, J.; Stratmann, F.; Sipilä, M.; Kulmala, M.; Herrmann, H. Gas-Phase Ozonolysis of Cycloalkenes: Formation of Highly Oxidized RO2 Radicals and Their Reactions with NO, NO2, SO2, and Other RO2 Radicals. J. Phys. Chem. A 2015, 119, 10336-10348.

(17) Kurtén, T.; Rissanen, M. P.; Mackeprang, K.; Thornton, J. A.; Hyttinen, N.; Jørgensen, S.; Kjaergaard, H. G. Computational Study of Hydrogen Shifts and RingOpening Mechanisms in $\alpha$ Pinene Ozonolysis Products. J. Phys. Chem. A. 2015, 119, $11366-11375$.

(18) Kurtén, T.; Tiusanen, K.; Roldin, P.; Rissanen, M. P.; Luy, J.; Boy, M.; Ehn, M.; Donahue, N. M. $\alpha$-pinene Autoxidation Products May Not Have Extremely Low Saturation Vapor Pressures Despite High O:C Ratios. J. Phys. Chem. A. 2016, 120, 2569-2582.

(19) Elm, J.; Myllys, N.; Hyttinen, N.; Kurtén, T. Computational Study of the Clustering of a Cyclohexene Autoxidation Product $\mathrm{C}_{6} \mathrm{H}_{8} \mathrm{O}_{7}$ with Itself and Sulfuric Acid. J. Phys. Chem. A 2015, 119, 8414-8421.

(20) Elm, J.; Myllys, N.; Luy, J.; Kurtén, T.; Vehkamäki, H. The Effect of Water and Bases on the Clustering of a Cyclohexene Autoxidation Product $\mathrm{C}_{6} \mathrm{H}_{8} \mathrm{O}_{7}$ with Sulfuric Acid. J. Phys. Chem. A 2016, 120, 2240-2249.

(21) Howard, D. L.; Kjaergaard, H. G. Hydrogen Bonding to Divalent Sulfur. Phys. Chem. Chem. Phys. 2008, 10, 4113-4118. 
(22) Andersen, C. L.; Jensen, C. S.; Mackeprang, K.; Du, L.; Jørgensen, S.; Kjaer-

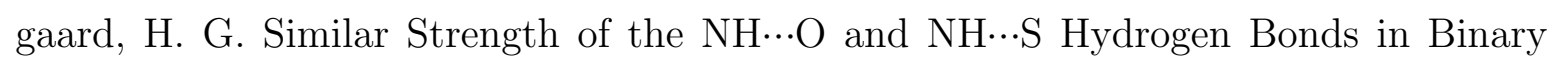
Complexes. J. Phys. Chem. A 2014, 118, 11074-11082.

(23) Jiang, X.; Liu, S.; Tsona, N. T.; Tang, S.; Ding, L.; Zhao, H.; Du, L. Matrix Isolation FTIR Study of Hydrogen-bonded Complexes of Methanol with Heterocyclic Organic Compounds. RSC Adv. 2017, 7, 2503-2512.

(24) Du, L.; Tang, S.; Hansen, A. S.; Frandsen, B. N.; Maroun, Z.; Kjaergaard, H. G. Subtle Differences in the Hydrogen Bonding of Alcohol to Divalent Oxygen and Sulfur. Chem. Phys. Lett. 2017, 667, 146-153.

(25) Møller, K. H.; Tram, C. M.; Kjaergaard, H. G. Side-by-Side Comparison of Hydroperoxide and Corresponding Alcohol as Hydrogen-Bond Donors. J. Phys. Chem. A. DOI: 10.1021/acs.jpca.7b01323.

(26) Du, L.; Kjaergaard, H. G. Fourier Transform Infrared Spectroscopy and Theoretical Study of Dimethylamine Dimer in the Gas Phase. J. Phys. Chem. A 2011, 115, 1209712104.

(27) Du, L.; Lane, J. R.; Kjaergaard, H. G. Identification of the Dimethylaminetrimethylamine Complex in the Gas Phase. J. Chem. Phys. 2012, 136, 184305.

(28) Du, L.; Mackeprang, K.; Kjaergaard, H. G. Fundamental and Overtone Vibrational Spectroscopy, Enthalpy of Hydrogen Bond Formation and Equilibrium Constant Determination of the Methanol-dimethylamine Complex. Phys. Chem. Chem. Phys. 2013, 15, 10194-10206.

(29) Hansen, A. S.; Du, L.; Kjaergaard, H. G. The Effect of Fluorine Substitution in Alcoholamine Complexes. Phys. Chem. Chem. Phys. 2014, 16, 22882-22891. 
(30) Zhao, H.; Chang, J.; Du, L. Effect of Hydrogen Bonding on the Spectroscopic Properties of Molecular Complexes with Aromatic Rings as Acceptors. Comp. Theor. Chem. 2016, $1084,126-132$.

(31) Hansen, A. S.; Maroun, Z.; Mackeprang, K.; Frandsen, B. N.; Kjaergaard, H. G. Accurate Thermodynamic Properties of Gas Phase Hydrogen Bonded Complexes. Phys. Chem. Chem. Phys. 2016, 18, 23831-23839.

(32) Hansen, A. S.; Du, L.; Kjaergaard, H. G. Positively Charged Phosphorus as a Hydrogen Bond Acceptor. J. Phys. Chem. Lett. 2014, 5, 4225-4231.

(33) Møller, K. H.; Hansen, A. S.; Kjaergaard, H. G. Gas Phase Detection of the NHP Hydrogen Bond and Importance of Secondary Interactions. J. Phys. Chem. A 2015, 119, 10988-10998.

(34) Jokinen, T.; Sipilä, M.; Junninen, H.; Ehn, M.; Lönn, G.; Hakala, J.; Petäjä, T.; Mauldin III, R. L.; Kulmala, M.; Worsnop, D. R. Atmospheric Sulphuric Acid and Neutral Cluster Measurements using CI-APi-TOF. Atmos. Chem. Phys. 2012, 12, $4117-4125$.

(35) Zhao, J.; Eisele, F. L.; Titcombe, M.; Kuang, C.; McMurry, P. H. Chemical Ionization Mass Spectrometric Measurements of Atmospheric Neutral Clusters using the Cluster CIMS. J. Geophys. Res. 2010, 115, D08205, doi:10.1029/2009JD012606.

(36) Ehn, M.; Kleist, E.; Junninen, H.; Petäjä, T.; Lönn, G.; Schobesberger, S.; Dal Maso, M.; Trimborn, A.; Kulmala, M.; Worsnop, D. R. et al. Gas Phase Formation of Extremely Oxidized Pinene Reaction Products in Chamber and Ambient Air. Atmos. Chem. Phys. 2012, 12, 5113-5127.

(37) Hyttinen, N.; Kupiainen-Määttä, O.; Rissanen, M. P.; Muuronen, M.; Ehn, M.; Kurtén, T. Modeling the Charging of Highly Oxidized Cyclohexene Ozonolysis Products Using Nitrate-Based Chemical Ionization. J. Phys. Chem. A. 2015, 119, 6339-6345. 
(38) Berndt, T.; Richters, S.; Jokinen, T.; Hyttinen, N.; Kurtén, T.; Otkjær, R. V.; Kjaergaard, H. G.; Stratmann, F.; Herrmann, H.; Sipilä, M. et al. Hydroxyl Radical-Induced Formation of Highly Oxidized Organic Compounds. Nat. Commun. 2016, 7, 13677, doi:10.1038/ncomms13677.

(39) Jen, C. N.; Zhao, J.; McMurry, P. H.; Hanson, D. R. Chemical Ionization of Clusters Formed from Sulfuric Acid and Dimethylamine or Diamines. Atmos. Chem. Phys. 2016, 16, 12513-12529.

(40) and M. P. Rissanen, N. H.; Kurten, T. Computational Comparison of Acetate and Nitrate Chemical Ionization of Highly Oxidized Cyclohexene Ozonolysis Intermediates and Products. J. Phys. Chem. A. 2017, 121, 2172-2179.

(41) Lee, B. H.; Lopez-Hilfiker, F. D.; Mohr, C.; Kurtén, T.; Worsnop, D. R.; Thornton, J. A. An Iodide-Adduct High-Resolution Time-of-Flight Chemical-Ionization Mass Spectrometer: Application to Atmospheric Inorganic and Organic Compounds. Environ. Sci. Technol. 2014, 48, 6309-6317.

(42) Iyer, S.; Lopez-Hilfiker, F.; Lee, B. H.; Thornton, J. A.; Kurtén, T. Modeling the Detection of Organic and Inorganic Compounds Using Iodide-Based Chemical Ionization. J. Phys. Chem. A. 2016, 120, 576-587.

(43) Gaussian 09, Revision B.01, M. J. Frisch, G. W. Trucks, H. B. Schlegel, G. E. Scuseria, M. A. Robb, J. R. Cheeseman, G. Scalmani, V. Barone, B. Mennucci, G. A. Petersson, et al., Gaussian, Inc., Wallingford CT, 2010.

(44) Werner, H.; Adler, T. B.; Manby, F. R. General Orbital Invariant MP2-F12 Theory. J. Chem. Phys. 2007, 126, 164102.

(45) Adler, T. B.; Knizia, G.; Werner, H. A Simple and Efficient CCSD(T)-F12 Approximation. J. Chem. Phys. 2007, 127, 221106. 
(46) Knizia, G.; Adler, T. B.; Werner, H. Simplified CCSD(T)-F12 Methods: Theory and Benchmarks. J. Chem. Phys. 2009, 130, 054104.

(47) Peterson, K. A.; Adler, T. B.; Werner, H. Systematically Convergent Basis Sets for Explicitly Correlated Wavefunctions: The Atoms H, He, B-Ne, and Al-Ar. J. Chem. Phys. 2008, 128, 084102.

(48) MOLPRO, version 2012.1, a package of ab initio programs, Werner H.-J., Knowles P. J., Knizia G., Manby F. R., Schütz M., Celani P., Korona T., Lindh R., Mitrushenkov A., Rauhut G. et al. , see http://www.molpro.net.

(49) Neese F., WIREs Comput Mol Sci 2012, 2: 73-78 doi: 10.1002/wcms.81.

(50) Elm, J.; Bilde, M.; Mikkelsen, K. V. Assessment of Density Functional Theory in Predicting Structures and Free Energies of Reaction of Atmospheric Prenucleation Clusters. J. Chem. Theory Comput. 2012, 8, 2071-2077.

(51) Elm, J.; Bilde, M.; Mikkelsen, K. V. Assessment of Binding Energies of Atmopsheric Clusters. Phys. Chem. Chem. Phys 2013, 15, 16442-16445.

(52) Leverentz, H. R.; Siepmann, J. I.; Truhlar, D. G.; Loukonen, V.; Vehkamäki, H. Energetics of Atmospherically Implicated Clusters Made of Sulfuric Acid, Ammonia, and Dimethyl Amine. J. Phys. Chem. A 2013, 117, 3819-3825.

(53) Elm, J.; Kristensen, K. Basis Set Convergence of the Binding Energies of Strongly Hydrogen-Bonded Atmospheric Clusters. Phys. Chem. Chem. Phys 2017, 19, 11221133.

(54) Bork, N.; Du, L.; Kjaergaard, H. G. Identification and Characterization of the HClDMS Gas Phase Molecular Complex via Infrared Spectroscopy and Electronic Structure Calculations. J. Phys. Chem. A 2014, 118, 1384-1389. 
(55) Bork, N.; Du, L.; Reimen, H.; Kurtén, T.; Kjaergaard, H. G. Benchmarking Ab Initio Binding Energies of Hydrogen-Bonded Molecular Clusters Based on FTIR Spectroscopy. J. Phys. Chem. A 2014, 118, 5316-5322.

(56) Myllys, N.; Elm, J.; Kurtén, T. Density Functional Theory Basis Set Convergence of Sulfuric Acid-Containing Molecular Clusters. Comp. Theor. Chem. 2016, 1098, 1-12.

(57) Elm, J.; Mikkelsen, K. V. Computational Approaches for Efficiently Modelling of Small Atmospheric Clusters. Chem. Phys. Lett. 2014, 615, 26-29.

(58) Hanwell, M. D.; Curtis, D. E.; Lonie, D. C.; Vandermeersch, T.; Zurek, E.; Hutchison, G. R. Avogadro: An Advanced Semantic Chemical Editor, Visualization, and Analysis Platform. J. Cheminform. 2012, 4, 1-17.

(59) Elm, J.; Kurtén, T.; Bilde, M.; Mikkelsen, K. V. Molecular Interaction of Pinic Acid with Sulfuric Acid - Exploring the Thermodynamic Landscape of Cluster Growth. J. Phys. Chem. A 2014, 118, 7892-7900.

(60) Kawamura, K. Identification of $\mathrm{C}_{2}-\mathrm{C}_{10}$ w-Oxocarboxylic Acids, Pyruvic Acid, and $\mathrm{C}_{2}-\mathrm{C}_{3}$ $\alpha$-Dicarbonyls in Wet Precipitation and Aerosol Samples by Capillary GC and GC/MS. Anal. Chem. 1993, 65, 3505-3511.

(61) Sempéré, R.; Kawamura, K. Comparative Distributions of Dicarboxylic Acids and Related Polar Compounds in Snow, Rain and Aerosols from Urban Atmosphere. Atmos. Environ. 1994, 28, 449-459.

(62) Khwaja, H. A. Atmospheric Concentrations of Carboxylic Acids and Related Compounds at a Semiurban Site. Atmos. Environ. 1995, 29, 127-139.

(63) Kawamura, K.; Kasukabe, H. Source and Reaction Pathways of Dicarboxylic Acids, Ketoacids and Dicarbonyls in Arctic Aerosols: One Year of Observations. Atmos. Environ. 1996, 30, 1709-1722. 
(64) Limbeck, A.; Puxbaum, H. Organic Acids in Continental Background Aerosols. Atmos. Environ. 1999, 33, 1847-1852.

(65) Kawamura, K.; Sempéré, R.; Imai, Y.; Fujii, Y.; Hayashi, M. Water Soluble Dicarboxylic Acids and Related Compounds in Antarctic Aerosols. J. Geophys. Res. 1996, 101, 187121-18728.

(66) Kawamura, K.; Sakaguchi, F. Molecular Distributions of Water Soluble Dicarboxylic Acids in Marine Aerosols over the Pacific Ocean Including Tropics. J. Geophys. Res. 1999, 104, 3501-3509.

(67) Simoneit, B. R. T.; Kobayashi, M.; Mochida, M.; Kawamura, K.; Lee, M.; Lim, H.; Turpin, J. B.; Komazaki, Y. Composition and Major Sources of Organic Compounds of Aerosol Particulate Matter Sampled During the ACE-Asia Campaign. J. Geophys. Res. 2004, 109, D19S10, doi:10.1029/2004JD004598.

(68) Kawamura, K.; Tachibana, E.; Okuzawa, K.; Aggarwal, S. G.; Kanaya, Y.; ; Wang, Z. F. High Abundances of Water-soluble Dicarboxylic Acids, Ketocarboxylic Acids and $\alpha$ dicarbonyls in the Mountaintop Aerosols Over the North China Plain During Wheat Burning Season. Atmos. Chem. Phys. 2013, 13, 8285-8302.

(69) Deshmukh, D. K.; Kawamura, K.; Lazaar, M.; Kunwar, B.; Boreddy, S. K. R. Dicarboxylic Acids, Oxoacids, Benzoic acid, $\alpha$-dicarbonyls, WSOC, OC, and Ions in Spring Aerosols from Okinawa Island in the Western North Pacific Rim: Size Distributions and Formation Processes. Atmos. Chem. Phys. 2016, 16, 5263-5282.

(70) Elm, J.; Jen, C. N.; Kurtén, T.; Vehkamäki, H. Strong Hydrogen Bonded Molecular Interactions between Atmospheric Diamines and Sulfuric Acid. J. Phys. Chem. A 2016, 120, 3693-3700.

(71) Myllys, N.; Elm, J.; Halonen, R.; Kurtén, T.; Vehkamäki, H. Coupled Cluster Evalu- 
ation of the Stability of Atmospheric Acid-Base Clusters with up to 10 Molecules. J. Phys. Chem. A 2016, 120, 621-630.

(72) Hoffmann, T.; Bandur, R.; Marggraf, U.; Linscheid, M. Molecular Composition of Organic Aerosols Formed in the $\alpha$-pinene $/ \mathrm{O}_{3}$ reaction: Implications for New Particle Formation Processes. J. Geophys. Res. 1998, 103, 25569-25578.

(73) Christoffersen, T. S.; Hjorth, J.; Horie, O.; Jensen, N. R.; Kotzias, D.; Molander, L. L.; Need, P.; Ruppert, L.; Winterhalter, R.; Virkkula, A. et al. Cis-Pinic Acid, a Possible Precursor for Organic Aerosol Formation from Ozonolysis of $\alpha$-pinene. Atmos. Environ. 1998, 32, 1657-1661.

(74) Yu, J.; Cocker III, D. R.; Griffin, R. H.; Flagan, R. C.; Seinfeld, J. H. Gas-Phase Ozone Oxidation of Monoterpenes: Gaseous and Particulate Products. J. Atmos. Chem. 1999, 34, 207-258.

(75) Glasius, M.; Duane, M.; Larsen, B. R. Determination of Polar Terpene Oxidation Products in Aerosols by Liquid Chromatography-ion Trap Mass Spectrometry. J. Chromatogr. A 1999, 833, 121-135.

(76) Larsen, B. R.; Bella, D. D.; Glasius, M.; Jensen, R. W. N. R.; Hjorth, J. Gas-Phase $\mathrm{OH}$ Oxidation of Monoterpenes: Gaseous and Particulate Products. J. Atmos. Chem. 2001, 38, 231-276.

(77) Szmigielski, R.; Surratt, J. D.; Gómez-González, Y.; Van der Veken, P.; Kourtchev, I.; Vermeylen, R.; Blockhuys, F.; Jaoui, M.; Kleindienst, T. E.; Lewandowski, M. et al. 3methyl-1,2,3-butanetricarboxylic Acid: An Atmospheric Tracer for Terpene Secondary Organic Aerosol. Geophys. Res. Lett. 2007, 34, doi:10.1029/2007GL031338.

(78) Müller, L.; Reinnig, M.; Naumann, K. H.; Saathoff, H.; Mentel, T. F.; Donahue, N. M.; Hoffmann, T. Formation of 3-methyl-1,2,3-butanetricarboxylic Acid via Gas Phase Ox- 
idation of Pinonic Acid - A Mass Spectrometric Study of SOA Aging. Atmos. Chem. Phys. 2012, 12, 1483-1496.

(79) Yasmeen, F.; Vermeylen, R.; Szmigielski, R.; Iinuma, Y.; Bøge, O.; Herrmann, H.; Maenhaut, W.; Claeys, M. Terpenylic Acid and Related Compounds: Precursors for Dimers in Secondary Organic Aerosol from the Ozonolysis of $\alpha$ - and $\beta$-pinene. Atmos. Chem. Phys. 2010, 10, 9383-9392.

(80) Yasmeen, F.; Szmigielski, R.; Vermeylen, R.; Gmez-Gonzlez, Y.; Surratt, J. D.; Chan, A. W. H.; Seinfeld, J. H.; Maenhaut, W.; Claeys, M. Mass Spectrometric Characterization of Isomeric Terpenoic Acids from the Oxidation of $\alpha$-pinene, $\beta$-pinene, d-limonene, and $\Delta^{3}$-carene in Fine Forest Aerosol. J. Mass Spectrom. 2011, 46, 425442.

(81) Kahnt, A.; Iinuma, Y.; Blockhuys, F.; Mutzel, A.; Vermeylen, R.; Kleindienst, T. E.; Jaoui, M.; Offenberg, J. H.; Lewandowski, M.; Bge, O. et al. 2-Hydroxyterpenylic Acid: An Oxygenated Marker Compound for $\alpha$-pinene Secondary Organic Aerosol in Ambient Fine Aerosol. Environ. Sci. Technol. 2014, 48, 4901-4908.

(82) Claeys, M.; Szmigielski, R.; Kourtchev, I.; Van der Veken, P.; Vermeylen, R.; Maenhaut, W.; Jaoui, M.; Kleindienst, T. E.; Lewandowski, M.; Offenberg, J. H. et al. Hydroxydicarboxylic Acids: Markers for Secondary Organic Aerosol from the Photooxidation of $\alpha$-Pinene. Environ. Sci. Technol. 2007, 41, 1628-1634.

(83) Claeys, M.; Iinuma, Y.; Szmigielski, R.; Surratt, J. D.; Blockhuys, F.; Van Alsenoy, C.; Bøge, O.; Sierau, B.; Gómez-González, Y.; Vermeylen, R. et al. Terpenylic Acid and Related Compounds from the Oxidation of $\alpha$-Pinene: Implications for New Particle Formation and Growth above Forests. Environ. Sci. Technol. 2009, 43, 6976-6982.

(84) Elm, J.; Myllys, N.; Olenius, T.; Halonen, R.; Kurtén, T.; Vehkamäki, H. Formation of 
Atmospheric Molecular Clusters Consisting of Sulfuric Acid and $\mathrm{C}_{8} \mathrm{H}_{12} \mathrm{O}_{6}$ Tricarboxylic Acid. Phys. Chem. Chem. Phys 2017, 19, 4877-4886.

(85) Partanen, L.; Vehkamäki, H.; K. Hansen, H. H., J. Elm; Kurtén, T.; Halonen, R.; Zapadinsky, E. Effect of Conformers on Free Energies of Atmospheric Complexes. J. Phys. Chem. A 2016, 120, 8613-8624.

(86) Kristensen, K.; Enggrob, K. L.; King, S. M.; Worton, D. R.; Platt, S. M.; Mortensen, R.; Rosenoern, T.; Surratt, J. D.; Bilde, M.; Goldstein, A. H. et al. Formation and Occurrence of Dimer Esters of Pinene Oxidation Products in Atmospheric Aerosols. Atmos. Chem. Phys. 2013, 13, 3763-3776.

(87) Kristensen, K.; Cui, T.; Zhang, H.; Gold, A.; Glasius, M.; Surratt, J. D. Dimers in $\alpha$-pinene Secondary Organic Aerosol: Effect of Hydroxyl Radical, Ozone, Relative Humidity and Aerosol Acidity. Atmos. Chem. Phys. 2014, 14, 4201-4218. 
Graphical TOC Entry

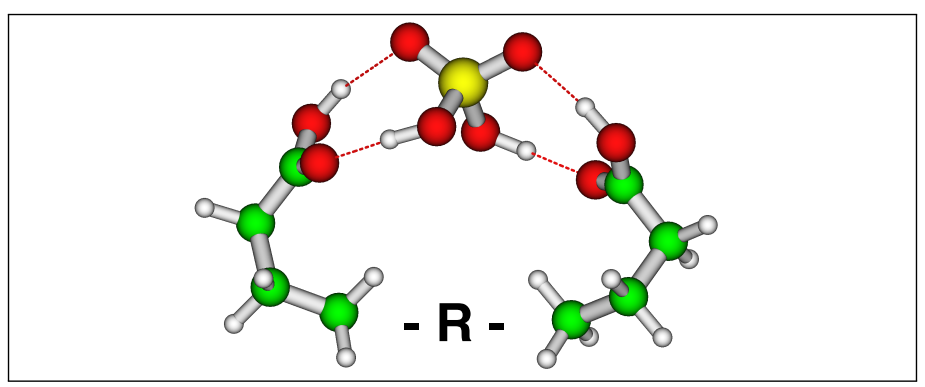

